\title{
Awareness and Knowledge of Dental Implants as a Treatment to Replace Missing Teeth Amongst Paramedical and Allied Health Sciences Students
}

\author{
Krishna Prasad D. ${ }^{1}$, Easha Singh Dogra ${ }^{2}$, Anupama Prasad D. ${ }^{3}$ \\ 1,2,3 Department of Prosthodontics, AB Shetty Memorial Institute of Dental Sciences, \\ NITTE (Deemed to Be University), Deralakatte, Karnataka, India.
}

\section{ABSTRACT}

\section{BACKGROUND}

Loss of natural dentition is a disease which leads to problems associated with mastication, speech, aesthetics and a person's psychology. Rehabilitation of the same is a necessity to restore the form and function of stomatognathic system. Many treatment options are available to restore the missing teeth. Rehabilitation using dental implants is a newer treatment option which helps in improving the function and self-confidence of the patient.

\section{METHODS}

This descriptive study was conducted amongst 200 students of Paramedical and Allied Health Sciences students. 200 students were divided in two groups, groups 1 (first year and second year students) and group 2 (third year and fourth year students). They were asked 20 questions related to awareness of implants as a treatment option to replace a missing tooth.

\section{RESULTS}

$22.5 \%$ of the students believed that it is important to replace missing teeth. More than half of the students were somewhat aware about the availability of dental implants as a treatment option for missing teeth. For $60.4 \%$ and $44.4 \%$ students of group 1 and 2, the source of knowledge about dental implants was from relatives and friends respectively. $59.4 \%$ and $76.8 \%$ of students from group 1 and group 2 respectively are ready to recommend implants as a treatment option to their patients.

\section{CONCLUSIONS}

$49.5 \%$ and $56.6 \%$ students from group 1 and group 2 respectively had heard about intraoral implants as an option of treatment. The overall cognizance is less amongst the students. Efforts should be made to increase awareness about dental implants amongst students so that their patients can also get benefitted and an overall increase in awareness and knowledge about dental implants is increased amongst the general public.

\section{KEY WORDS}

Awareness, Implant Supported Prosthesis, Treatment Option
Corresponding Author: Dr. Anupama Prasad D, Reader, Department of Prosthodontics, $A B$ Shetty Memorial Institute of Dental Sciences, NITTE (Deemed to Be University), Deralakatte-575018, Mangaluru, Karnataka, India.

E-mail: dranupamaprasad@nitte.edu.in

DOI: $10.14260 /$ jemds/2021/26

How to Cite This Article:

Prasad DK, Dogra ES, Prasad DA, et al. Awareness and knowledge of dental implants as a treatment to replace missing teeth amongst paramedical and allied health sciences students. J Evolution Med Dent Sci 2021;10(03):123-126, DOI: 10.14260/jemds/2021/26

Submission 18-02-2020,

Peer Review 28-10-2020,

Acceptance 03-11-2020,

Published 18-01-2021.

Copyright (C) 2021 JEMDS. This is an open access article distributed under Creative Commons Attribution License [Attribution 4.0 International (CC BY 4.0)] 


\section{BACKGROUND}

Edentulousness either partial or complete is a major ailment. It is popularly linked to aesthetic, psychosocial and functional shortcomings since times immemorial. ${ }^{1}$ Reconstruction and repair of this loss is mainly by substituting the lost dentition with artificial replacement of teeth either in the form of dentures which are fixed or removable restoring the lost appearance and function. The replacement should in fact camouflage the defect in total.

Dental implantology is a rapidly growing speciality in the field of dentistry. Dental implant simulates the radicular part of tooth, surgically placed into the ostium to support a replacement tooth / tooth, partial or complete dentures or maxillofacial prosthesis. $^{2}$ With the advancement in technology, implant supported prosthesis are being widely used to replace missing teeth. Dental implant treatment provides excellent long-term results in rehabilitation of partially or completely edentulous patients. It preserves the properties such as retention and stability of denture, masticatory efficiency and life quality.

There has been seen an increased awareness amongst all individuals about novel options of treatment in the form of implants for substitution of missing teeth. The aim of this study is to determine the awareness of dental implant as a treatment options for replacement of missing teeth in Paramedical students and Allied Health Sciences students.

The paramedical staff and allied health workers form a significant part of the hospital manpower apart from the medical doctors and dental specialists. They play a very important role in awareness among the masses as they are in a constant interactive session with the patients and the general public. They act as educators for the general public and their knowledge about the treatment option may prove beneficial for the patient.

In this study a survey of the cognizance of dental implants as a choice of substitution of missing tooth among paramedical students and allied health students was evaluated.

\section{METHODS}

A descriptive study was designed. Stratified random sampling technique was used for the purpose of the study. All the participants were made aware of the aims and objectives of the study and informed consent was obtained. The printed questionnaire survey forms were distributed amongst 200 paramedical and allied health sciences students, 100 belonging to first and second year and 100 from third and fourth year. Sample size was selected on the basis of review of literature of the previous research. The formula used for estimating the sample size was, $\mathrm{n}=4 \mathrm{pq} / \mathrm{d}^{2}, \mathrm{p}=8, \mathrm{q}=92, \mathrm{~d}=4, \mathrm{n}=4 * 8 *$ $92 / 4^{\wedge} 2=184$ which is rounded off to 200 .

The questionnaire consisted of 20 questions which were validated out of which 10 were designed to assess the knowledge and awareness regarding implants as a treatment option and their willingness to recommend it to their patients and another 10 questions were related to their general knowledge regarding various prosthetic treatment options.

\section{Statistical Analysis}

Descriptive statistics were generated, to analyze the responses. Percentage values were used, and Chi-square test was done for comparison between the two groups. The level of significance was set at 0.05 .

\section{RESULTS}

200 students divided into groups 1 and group 2 to assess difference in opinion regarding the subject between the two groups. Both the groups were asked 20 questions related to knowledge and awareness of implants as option of treatment to replace a missing tooth. $14.9 \%$ and $24.2 \%$ of the students from group 1 and group 2 respectively had missing tooth. A total of $22.5 \%$ students believe that replacement of missing tooth is very important. 49.5 and $56.6 \%$ students from group 1 and group 2 respectively had somewhat heard about implants as a treatment option for missing dentition. Only 6.5 $\%$ of the total students are aware of the dental implants to a large extent. $78.2 \%$ and $82.8 \%$ from group 1 and group 2 respectively believe that fixed replacement options have advantage over the removable option. $31 \%$ of the total students believe that fixed rehabilitation is as good as one's own teeth. $60.4 \%$ and $44.4 \%$ students of group 1 and 2 had heard about implants from friends and relatives respectively and $23.8 \%$ and $20.2 \%$ students of group 1 and group 2 respectively know about the treatment option from books, newspapers and magazines. $30.5 \%$ of the total students would definitely like to know more about dental implants and only 4 $\%$ of the total students are not interested in knowing about the treatment option. $19.8 \%$ and $15.2 \%$ students of group 1 and 2 respectively believe that dental implants will last a lifetime. $62.6 \%$ of group 2 students believe implants and natural dentition needs the same hygiene care. According to the opinion of the participant students in the study high cost and need for the surgery is a major disadvantage for the treatment option. $68 \%$ and $78 \%$ of the group 2 students of the total students would like to recommend implant as a treatment option to their patients.

\begin{tabular}{|c|c|c|c|c|}
\hline Questions & Responses & Group 1 & Group 2 & Total \\
\hline \multirow{2}{*}{$\begin{array}{l}\text { 1. Do you have any } \\
\text { missing teeth? }\end{array}$} & Yes & $\begin{array}{c}15 \\
14.9 \%\end{array}$ & $\begin{array}{c}24 \\
24.2 \%\end{array}$ & $\begin{array}{c}39 \\
19.5 \%\end{array}$ \\
\hline & No & $\begin{array}{c}86 \\
85.1 \%\end{array}$ & $\begin{array}{c}75 \\
75.8 \%\end{array}$ & $\begin{array}{c}161 \\
80.5 \%\end{array}$ \\
\hline \multirow{5}{*}{$\begin{array}{l}\text { 2. Do you think the } \\
\text { replacement of } \\
\text { missing } \\
\text { Teeth is important? }\end{array}$} & Very important & $\begin{array}{c}21 \\
20.8 \%\end{array}$ & $\begin{array}{c}24 \\
24.2 \%\end{array}$ & $\begin{array}{c}45 \\
22.5 \%\end{array}$ \\
\hline & Somewhat important & $\begin{array}{c}60 \\
59.4 \%\end{array}$ & $\begin{array}{c}57 \\
57.6 \%\end{array}$ & $\begin{array}{c}117 \\
58.5 \%\end{array}$ \\
\hline & \multirow{2}{*}{$\begin{array}{c}\text { Neither important } \\
\text { nor unimportant }\end{array}$} & 18 & 13 & 31 \\
\hline & & $17.8 \%$ & $13.1 \%$ & $15.5 \%$ \\
\hline & Not important at all & $\begin{array}{c}2 \\
2.0 \%\end{array}$ & $\begin{array}{c}5 \\
5.1 \%\end{array}$ & $\begin{array}{c}7 \\
3.5 \%\end{array}$ \\
\hline \multirow{4}{*}{$\begin{array}{l}\text { 3. To what extent are } \\
\text { you aware of the } \\
\text { different treatment } \\
\text { options available? }\end{array}$} & To a large extent & $\begin{array}{c}4 \\
4.0 \%\end{array}$ & $\begin{array}{c}9 \\
9.1 \%\end{array}$ & $\begin{array}{c}13 \\
6.5 \%\end{array}$ \\
\hline & To a moderate extent & $\begin{array}{c}53 \\
52.5 \%\end{array}$ & $\begin{array}{c}49 \\
49.5 \%\end{array}$ & $\begin{array}{c}102 \\
51.0 \%\end{array}$ \\
\hline & To some extent & $\begin{array}{c}39 \\
38.6 \%\end{array}$ & $\begin{array}{c}34 \\
34.3 \%\end{array}$ & $\begin{array}{c}73 \\
36.5 \%\end{array}$ \\
\hline & Not at all & $\begin{array}{c}5 \\
5.0 \%\end{array}$ & $\begin{array}{c}7 \\
7.1 \%\end{array}$ & $\begin{array}{c}12 \\
6.0 \%\end{array}$ \\
\hline \multirow{2}{*}{$\begin{array}{c}\text { 4. Which Tooth } \\
\text { replacement has an } \\
\text { advantage in your } \\
\text { view? }\end{array}$} & $\begin{array}{l}\text { Removable } \\
\text { Replacement }\end{array}$ & $\begin{array}{c}22 \\
21.8 \%\end{array}$ & $\begin{array}{c}17 \\
17.2 \%\end{array}$ & $\begin{array}{c}39 \\
19.5 \%\end{array}$ \\
\hline & Fixed Replacement & $\begin{array}{c}79 \\
78.2 \%\end{array}$ & $\begin{array}{c}82 \\
82.8 \%\end{array}$ & $\begin{array}{c}161 \\
80.5 \%\end{array}$ \\
\hline
\end{tabular}




\begin{tabular}{|c|c|c|c|c|}
\hline Questions & Responses & Group 1 & Group 2 & Total \\
\hline \multirow{8}{*}{$\begin{array}{l}\text { 1. Would you like to know } \\
\text { more about dental implants? }\end{array}$} & \multirow{2}{*}{ Definitely } & 29 & 32 & 61 \\
\hline & & $28.7 \%$ & $32.3 \%$ & $30.5 \%$ \\
\hline & \multirow{2}{*}{ Likely } & 43 & 31 & 74 \\
\hline & & $42.6 \%$ & $31.3 \%$ & $37.0 \%$ \\
\hline & \multirow{2}{*}{ Maybe } & 27 & 30 & 57 \\
\hline & & $26.7 \%$ & $30.3 \%$ & $28.5 \%$ \\
\hline & \multirow{2}{*}{ Definitely Not } & 2 & 6 & 8 \\
\hline & & $2.0 \%$ & $6.1 \%$ & $4.0 \%$ \\
\hline \multirow{8}{*}{$\begin{array}{l}\text { 2. How long do you think a } \\
\text { dental implant lasts? }\end{array}$} & \multirow{2}{*}{ Lifetime } & 20 & 15 & 35 \\
\hline & & $19.8 \%$ & $15.2 \%$ & $17.5 \%$ \\
\hline & \multirow{2}{*}{ More than 10 years } & 43 & 34 & 77 \\
\hline & & $42.6 \%$ & $34.3 \%$ & $38.5 \%$ \\
\hline & \multirow{2}{*}{$<5-10$ years } & 26 & 27 & 53 \\
\hline & & $25.7 \%$ & $27.3 \%$ & $26.5 \%$ \\
\hline & \multirow{2}{*}{ Not Sure } & 12 & 23 & 35 \\
\hline & & $11.9 \%$ & $23.2 \%$ & $17.5 \%$ \\
\hline \multirow{7}{*}{$\begin{array}{l}\text { 3. What do you think is the } \\
\text { disadvantage of dental } \\
\text { implant in your view? }\end{array}$} & \multirow{3}{*}{ Need for Surgery } & $36.6 \%$ & $32.3 \%$ & $34.5 \%$ \\
\hline & & 33 & 38 & 71 \\
\hline & & $32.7 \%$ & $38.4 \%$ & $35.5 \%$ \\
\hline & \multirow{2}{*}{ Long Treatment Time } & 17 & 14 & 31 \\
\hline & & $16.8 \%$ & $14.1 \%$ & $15.5 \%$ \\
\hline & \multirow{2}{*}{ Not Aware } & 14 & 15 & 29 \\
\hline & & $13.9 \%$ & $15.2 \%$ & $14.5 \%$ \\
\hline \multirow{4}{*}{$\begin{array}{c}\text { 4. Do you think implant } \\
\text { placement is an invasive } \\
\text { procedure? }\end{array}$} & \multirow{2}{*}{ Yes } & 77 & 72 & 149 \\
\hline & & $76.2 \%$ & $72.7 \%$ & $74.5 \%$ \\
\hline & \multirow{2}{*}{ No } & 24 & 27 & 51 \\
\hline & & $23.8 \%$ & $27.3 \%$ & $25.5 \%$ \\
\hline
\end{tabular}
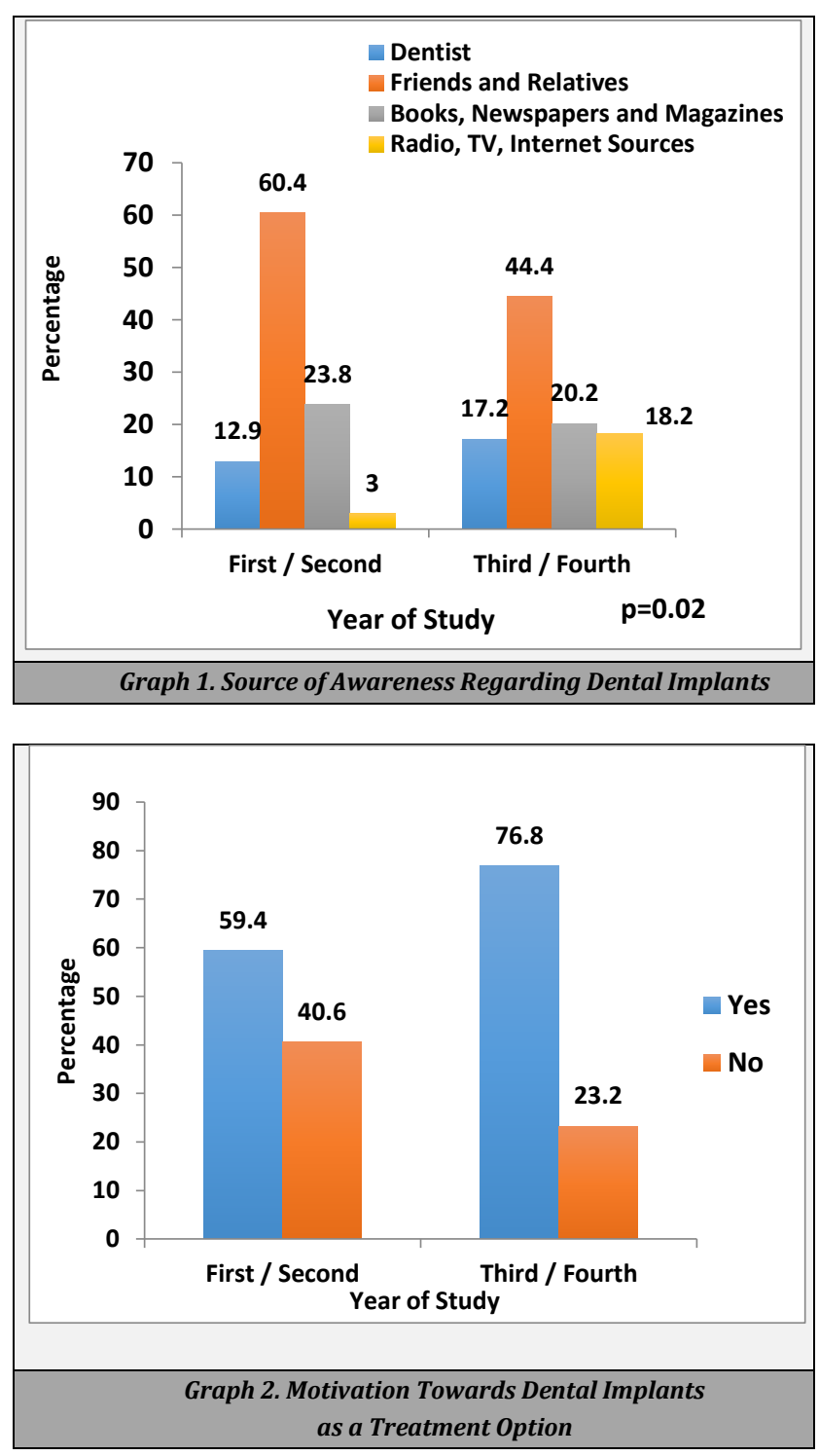

\section{DISCUSSION}

Dental implants are the norm of today's prosthetic and restorative dentistry. Reasons for tooth loss are several. Diseases of gums and bone, tooth decay, trauma and operator induced loss. All these can diminish the patient confidence. Replaced teeth are secured in place with the aid of intra oral implants simulating a natural root portion of a tooth. Complete dentures which are removable have several shortcomings. Lack of stability decreased functional ability etc., which could be overcome by implants. Dental implants stand to be much superior alternatives which provide a stable foundation and improve the life quality and comfort of the patient.

At present, dental implants are best accepted as a prosthetic treatment in partial and complete edentulous patients. Various studies have been done to assess the biocompatibility of different implants and it was found that dental implants are a satisfactory replacement for the teeth and made of materials which are well accepted by the body. Knowledge of dental implant must be made available to the patients to aid them in the selection as most relevant option. Different countries based on several studies have demonstrated various levels of understanding about the treatment options pertaining to dental implants

Information regarding the use of dental implant can be obtained by various means like health sector worker, television, journals, friends, internet, and advertisements.

In the present survey, self-administered structured questionnaires were given to 200 Paramedical and Allied Health Sciences students and the students were categorised into two groups, 1 and 2, group 1 consisted of students of first and second year and group 2 consisted of third and fourth years. The students belonged to the age group of 19 - 25 years. $58.5 \%$ (117) students believed replacement of missing teeth is somewhat important. $24.2 \%$ students of group 2 believed that replacement of teeth is very important. It is in accordance with Mayya et al. ${ }^{2}$ in their study $21.9 \%$ of those questioned felt need of replacement of teeth merely to close any visible gap.

$49.5 \%$ and $56.6 \%$ students from group 1 and group 2 respectively have somewhat heard about dental implants as substitutes to lost teeth as compared to a study done by Sheth et $\mathrm{al}^{3}$ where approximately more than $95 \%$ interns were aware of implants as a treatment option.

When asked which is better replacement option removable prosthesis or fixed prosthesis $80.5 \%$ (161) students believed fixed prosthesis had more advantage. When asked where they obtained knowledge about dental implants, a significant difference was seen in the options and both, groups 1 and 2 had heard more from friends and relatives 60.4 $\%$ and $44.4 \%$ respectively. Sheth et al $^{3}$ found $20 \%$ had heard it from other sources. In the study conducted by Rustemeyer and Bremerich ${ }^{4}$ reported that the contribution of internet, books, and magazines was very low which is in concurrence with the present study.

$28.7 \%$ and $32.3 \%$ students would definitely like to know more about dental implants from group 1 and group 2. Only $17.5 \%$ (35) students, 20 from group 1 and 15 from group 2 believed that implants last a lifetime. 
Sheth et $\mathrm{al}^{3}$ saw $50 \%$ interns approximately rated long-term survival of implant. Whereas in 2015 a study conducted by Chaudhary et $\mathrm{al}^{5}$ asked about the persistence of implants, $17.1 \%$ of respondents believed that replacement treatment with implants are a permanent solution substantiating results of the present study

High cost of placement (34.5\%) and surgical placement $(35.5 \%)$ is considered a disadvantage for implant placement by most of the students. In a study by Deebs et $\mathrm{al}^{6}$ it was found that majority of the people believed cost of the procedure is a major factor for not opting for this treatment option. $68 \%$ (136) students would recommend implant as a treatment option to their patients. $61.5 \%$ interns in 2013 showed a positive attitude toward including implant in clinical practice in a survey conducted by Shethet al. ${ }^{3} \mathrm{~A}$ recent study by Kohli et al. ${ }^{7}$ concluded that over $80 \%$ of the study group felt the high cost was a deterrent. These results are in agreement with most of the previously mentioned studies conducted by Zimmer et $\mathrm{al}^{8}$ and Tepper et al. ${ }^{9}$

In present survey it was seen that the awareness and knowledge gained by students about implants is less obtained from books or from their dentist. It is believed that short term courses should be provided to the students to increase their knowledge about dental implants as they play a major role in further educating their patients about treatment options.

Considering the general knowledge amongst the participants regarding various other prosthetic treatment options for replacement of the lost teeth, fixed treatment option was preferred by most of the participants.

\section{CONCLUSIONS}

$49.5 \%$ and $56.6 \%$ students from group 1 and group 2 respectively had heard about dental implants to a small extent as a treatment option. $11 \%$ of the student that is 22 students out of 200 knew about dental implants and $53 \%$ of the students were to a small degree aware of the implant therapy as an option to replace missing teeth. So, the overall knowledge amongst the students was low. Only $68 \%$ showed a positive attitude towards implant therapy and were willing to recommend implant as a treatment option to their patients. Efforts should be made to increase the awareness about dental implants amongst the students so that their patients can also get benefitted and an overall increase in awareness and knowledge about dental implants is increased amongst the general public.

Data sharing statement provided by the authors is available with the full text of this article at jemds.com.

Financial or other competing interests: None.

Disclosure forms provided by the authors are available with the full text of this article at jemds.com.

The authors thank NITTE (Deemed to Be University), Deralakatte, Mangaluru.

\section{REFERENCES}

[1] Mgbeokwere U, Okoye L, Ekwueme O. A survey of the knowledge of dental implants as a choice in treatment of edentulous jaws among health workers in Government Dental Clinics in Enugu. Ann Med Health Sci Res 2011;1(1):91-6.

[2] Mayya A, D'Souza J, George AM, et al. Knowledge and awareness of dental implants as a treatment choice in adult population in South India: a hospital-based study. Indian J Dent Res 2018;29(3):263-7.

[3] Sheth TS, Shah SS, Thakore DS, et al. Contemporary dental implant knowledge and attitude: a perspective of budding dentists. J Dent Implants 2017;7(2):54-8.

[4] Rustemeyer J, Bremerich A. Patients' knowledge and expectations regarding dental implants: assessment by questionnaire. Int J Oral Maxillofacial Surg 2007;36(9):814-7.

[5] Chaudhary S, Gowda TM, Kumar TAB, et al. Knowledge and attitudes of dental interns in Karnataka state, India, regarding implants. J Dent Educ 2013;77(10):1365-70.

[6] Deeb G, Wheeler B, Jones M, et al. Public and patient knowledge about dental implants. J Oral Maxillofac Surg 2017;75(7):1387-91

[7] Kohli S, Bhatia S, Kaur A, et al. Patients awareness and attitude towards dental implants. Indian J Dent 2015;6(4):167-71.

[8] Zimmer CM, Zimmer WM, Williams J, et al. Public awareness and acceptance of dental implants. Int J Oral Maxillofac Implants 1992;7(2):228-32.

[9] Tepper G, Haas R, Mailath G, et al. Representative marketing - oriented study on implants in the Austrian population. II. Implant acceptance, patient-perceived cost and patient satisfaction. Clin Oral Implants Res 2003;14(5):634-42. 